\title{
Dry matter and water dynamics of wheat grains in response to source reduction at different phases of grain filling
}

\author{
Claudia I. Harcha ${ }^{1 *}$, and Daniel F. Calderini ${ }^{1}$
}

Agreement that wheat (Triticum aestivum L.) is scarcely limited by source of assimilates during grain fill has not been confirmed when source was drastically decrease in high yield potential environments. Dry matter (DM) and water dynamics of growing grains being possibly able to explain grain weight $(\mathrm{GW})$ responses to source-sink ratios $\left(\mathrm{S}-\mathrm{S}_{\text {ratios }}\right)$ in these conditions. Objectives were to evaluate response of GW to $S-S_{\text {ratios }}$ at different phases during grain fill, and relationship

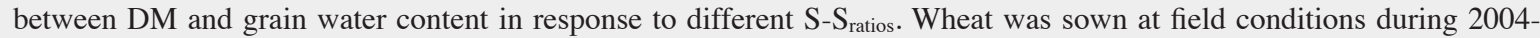

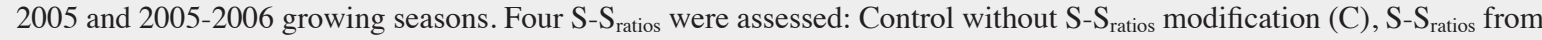
anthesis $(A t)+12 d$ to physiological maturity $\left(\mathrm{Sh}_{\mathrm{All}}\right), \mathrm{S}-\mathrm{S}_{\text {ratios }}$ from At $+12 \mathrm{~d}$ to first half of grain fill $\left(\mathrm{Sh}_{1 \mathrm{st}}\right)$ and from second half of grain fill to maturity $\left(\mathrm{Sh}_{2 n d}\right)$. Thousand grain weight $(\mathrm{TGW}), \mathrm{GW}$ at individual positions (IGW), stabilized grain water content (SGWC) and grain filling rate (GFR) were measured. TGW sensitivity to S-S ratios varied according to length of treatment and its timing, i.e. $\mathrm{Sh}_{\mathrm{All}}, \mathrm{Sh}_{1 \mathrm{st}}$, and $\mathrm{Sh}_{2 \text { nd }}$ treatments reduced TGW by $48 \%, 26 \%$, and $22 \%$, respectively. These reductions were little higher when IGW were evaluated in $\mathrm{Sh}_{\text {All }}$ (i.e. 53\%) and $\mathrm{Sh}_{1 \text { st }}$ (i.e. 33\%) treatments and lower in $\mathrm{Sh}_{2 \text { nd }}$ (i.e. 12\%). SGWC sensitivity was lower than that of IGW across $\mathrm{S}-\mathrm{S}$ ratios (e.g. $\mathrm{Sh}_{\text {All }} 27 \%, \mathrm{Sh}_{1 \mathrm{st}} 22 \%$, and $\mathrm{Sh}_{2 \text { nd }} 5 \%$ ). However, close association between IGW and SGWC $\left(\mathrm{R}^{2}=0.78, \mathrm{p} \leq 0.001\right)$ and between GFR and SGWC $\left(\mathrm{R}^{2}=0.98, \mathrm{p} \leq\right.$ 0.001 ) was found regardless of $\mathrm{S}-\mathrm{S}_{\text {ratios }}$ and seasons.

Key words: Grain filling, grain water content, grain weight, shading, source-sink ratio, Triticum aestivum.

\section{INTRODUCTION}

The knowledge of plant constraints limiting yield potential during the grain filling period is necessary to develop breeding and management strategies aimed at increasing harvestable yields. Currently, the assessment of different source-sink ratios during grain filling has shown that wheat (Triticum aestivum L.) is mainly sinklimited (Slafer and Savin, 1994; Borrás et al., 2004; Zhang et al., 2010); however, Sandaña et al. (2009) working in a high-yield environment, found that wheat is more affected by the source shortage than generally assumed. The physiological bases accounting for the responses reported by Sandaña et al. (2009) are especially important in southern Chile, taking into account that crop production systems are based on temperate cereals, which are favored by high grain weight potential. Thus, a better understanding of the causes behind the higher-thanexpected sensitivity of wheat-to-source reduction could improve the knowledge of physiological traits controlling grain weight of wheat in favorable environments.

${ }^{1}$ Universidad Austral de Chile, Facultad de Ciencias Agrarias, Campus Isla Teja, Valdivia, Chile.

*Corresponding author (claudiaharcha@gmail.com).

Received: 18 February 2014.

Accepted: 24 September 2014.

doi:10.4067/S0718-58392014000400002
Several studies have assessed the effect of different source-sink ratios on wheat yield and grain weight (Fischer and Laing, 1976; Fischer, 1985; Savin and Slafer, 1991; Slafer and Savin, 1994; Borrás et al., 2004; Sandaña et al., 2009; Serrago et al., 2013); but less information is available about the mechanisms involved in the sourcesink response. Given that grain water content has been found to be a key trait in determining wheat grain weight (Egli, 1990; Saini and Westgate, 2000; Pepler et al., 2006, Hasan et al., 2011), and considering the close balance between water and DM in growing grains (Schnyder and Baum, 1992; Calderini et al., 2000; Saini and Westgate, 2000; Pepler et al., 2006), studying grain water content in response to the source-sink reduction during grain filling could provide useful information on grain growth and its responsiveness to source constraints of wheat as has been shown in maize (Borrás et al., 2003; Borrás and Westgate, 2006).

The sensitivity of wheat to source-sink ratios at different times during the grain filling has not been fully investigated in wheat. This aspect is clearly relevant considering that wheat could be affected by source shortage at different moments during grain filling, thereby forcing the crop to use reserves, which could be insufficient to fill the grains, particularly under high yield conditions (Calderini et al., 2006; Sandaña et al., 2009; Serrago et al., 2013). Therefore, the sensitivity of wheat to source reductions 
at different phases during grain filling could differentially affect harvestable yields. Although this information has important consequences for wheat management, for example to control foliar diseases (Serrago et al., 2011), the wheat response to source reduction at different grain filling intervals is still largely unknown.

Borrás et al. (2004) hypothesized that growing wheat grains are more sensitive to source-sink manipulations before the grains reach the maximum water content and they are less affected later. The physiological assumption of this hypothesis is that source reduction at the onset of grain growth decreases maximum water content, thus, setting a lower sink size that cannot be reached if the source limitation is removed afterwards. In addition, maximum or stabilized wheat grain water content is reached at $25 \%$ of its relative grain filling period (Schnyder and Baum, 1992; Hasan et al., 2011) and at $35 \%$ of its final grain dry weight (Borrás et al., 2004); therefore, grain weight may be more sensitive to changes in the source-sink ratio if this occurs early in grain filling. The positive relationships among water content, DM and grain volume found in wheat (Hasan et al., 2011) support these considerations. Despite such evidences, the hypothesis proposed by Borrás et al. (2004) has not yet been accomplished in wheat.

The aim of the present study was to assess the response of grain yield and components of wheat to different sourcesink ratios during the grain filling period to evaluate the sensitivity of grain weight to source reductions at different phases during grain filling and the relationship between DM and water dynamics of grains under different sourcesink ratios.

\section{MATERIALS AND METHODS}

\section{Site, treatments, and experimental design}

Three field experiments evaluating spring wheat were carried out at the experimental field of the Universidad Austral de Chile in Valdivia (39\%47' S, 7314' W, 19 $\mathrm{m}$ a.s.1.), Chile. Experiments were conducted in two successive seasons, during the 2004-2005 (at two sowing dates, called herein Experiments 1 and 2) and 2005-2006 (Experiment 3) growing seasons in a Typic Hapludand soil. The treatments consisted of four source-sink ratios, i.e., control without source-sink ratio modification $(\mathrm{C})$, lower source-sink ratio from anthesis (At) $+12 \mathrm{~d}$ to physiological maturity (PM) (hereafter $\mathrm{Sh}_{\mathrm{All}}$ ), source reduction from At $+12 \mathrm{~d}$ to the first half of grain filling $\left(\mathrm{Sh}_{1 \mathrm{st}}\right)$, and from the second half of grain filling to PM $\left(\mathrm{Sh}_{2 n d}\right)$. Figure 1 and Table 1 provide a complete picture of the timings of treatments and climatic variables. The experiments were arranged in a split-split-plot design with three replicates, where experiments were assigned to the main plots, cultivars to sub-plots, and source-sink treatments to sub-sub-plots.

\section{Management of the experiments}

Two wheat cultivars (Huayún-INIA and Otto Baer) were sown on 25 August 2004 (Experiment 1), 18 October 2004 (Experiment 2), and 26 September 2005 (Experiment 3). Plots consisted of six rows, $2 \mathrm{~m}$ long, and $0.15 \mathrm{~m}$ apart. Seed rates were 250,320 , and 350 seeds $\mathrm{m}^{-2}$ in Experiments 1, 2, and 3, respectively. Between 1 and 3-mo prior to sowing, $7 \mathrm{Mg} \mathrm{CaCO}_{3} \mathrm{ha}^{-1}$ were applied on plots to avoid Al toxicity, which is usual in the acidic soils of southern Chile (Typic Hapludand). According with soil

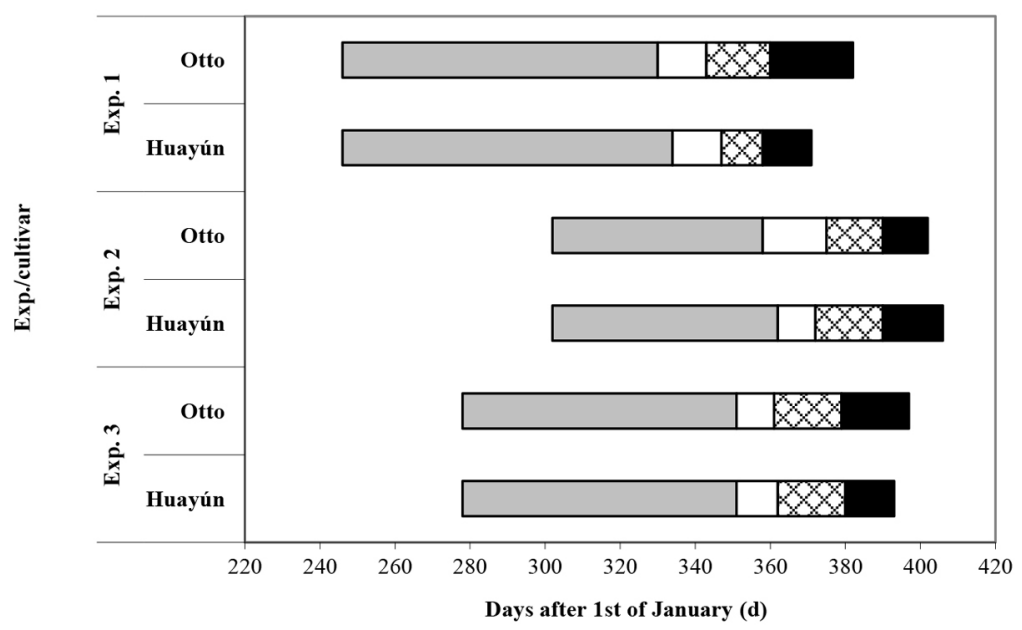

Entire bars show the crop season from emergence to physiological maturity in the control treatment. 1 January is assigned to 1 in the abscissa axis, representing consecutive days.

Figure 1. Crop phenology of wheat 'Otto Baer' and 'Huayún-INIA' from emergence to physiological maturity. Bars show emergence to anthesis (grey bars), anthesis to beginning of source-sink reductions (white bars), and source-sink reductions in control (beginning of source-sink reductions to physiological maturity, until end bar), entire cycle (grated and black bar coupled), first half (grated bars), and second half (black bars) during 2004-2005 (Experiments 1 and 2) and 2005-2006 (Experiment 3) growing seasons. 
Table 1. Treatment duration (days and degree-days) and cumulative intercepted photosynthetically active radiation (CI-PAR) from anthesis

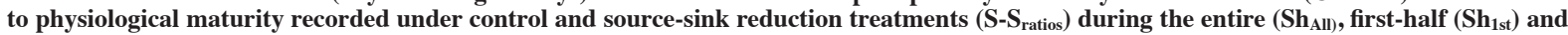
second-half $\left(\mathrm{Sh}_{2 \mathrm{st}}\right)$ phases of the grain filling period of wheat 'Otto Baer' and 'Huayún-INIA' during the 2004-2005 (Experiments 1 and 2 ) and 2005-2006 (Experiment 3) growing seasons.

\begin{tabular}{|c|c|c|c|c|c|c|c|c|c|c|}
\hline \multirow{4}{*}{ Cultivar } & \multirow{4}{*}{ S-S $\mathrm{S}_{\text {ratios }}$} & \multicolumn{9}{|c|}{ Grain filling period } \\
\hline & & \multicolumn{3}{|c|}{ Experiment 1} & \multicolumn{3}{|c|}{ Experiment 2} & \multicolumn{3}{|c|}{ Experiment 3} \\
\hline & & \multicolumn{2}{|c|}{ Treatment duration } & \multirow{2}{*}{$\frac{\text { CI-PAR }}{\mathrm{MJ} \mathrm{m}^{-2}}$} & \multicolumn{2}{|c|}{ Treatment duration } & \multirow{2}{*}{$\frac{\text { CI-PAR }}{\mathrm{MJ} \mathrm{m}^{-2}}$} & \multicolumn{2}{|c|}{ Treatment duration } & \multirow{2}{*}{$\frac{\text { CI-PAR }}{\mathrm{MJ} \mathrm{m}^{-2}}$} \\
\hline & & $\mathrm{d}$ & ${ }^{\circ} \mathrm{Cd}$ & & $\mathrm{d}$ & ${ }^{\circ} \mathrm{C} \mathrm{d}$ & & $\mathrm{d}$ & ${ }^{\circ} \mathrm{C} \mathrm{d}$ & \\
\hline \multirow[t]{4}{*}{ Otto Baer } & Control & 52 & 837 & 578 & 44 & 747 & 539 & 46 & 839 & 553 \\
\hline & $\mathrm{Sh}_{\mathrm{All}}$ & 39 & 646 & 180 & 27 & 489 & 241 & 36 & 617 & 176 \\
\hline & $\mathrm{Sh}_{1 \mathrm{st}}$ & 17 & 282 & 422 & 15 & 273 & 375 & 18 & 299 & 380 \\
\hline & $\mathrm{Sh}_{2 \mathrm{nd}}$ & 22 & 382 & 337 & 12 & 234 & 405 & 18 & 318 & 349 \\
\hline \multirow[t]{4}{*}{ Huayún-INIA } & Control & 37 & 605 & 405 & 44 & 727 & 534 & 42 & 768 & 507 \\
\hline & $\mathrm{Sh}_{\mathrm{All}}$ & 24 & 396 & 170 & 34 & 613 & 167 & 31 & 527 & 184 \\
\hline & $\mathrm{Sh}_{1 \mathrm{st}}$ & 11 & 180 & 309 & 18 & 273 & 334 & 18 & 296 & 332 \\
\hline & $\mathrm{Sh}_{2 \mathrm{nd}}$ & 13 & 233 & 266 & 16 & 234 & 367 & 13 & 231 & 359 \\
\hline
\end{tabular}

analysis and based upon local recommendations (Instituto de Ingeniería Agraria y Suelos, Universidad Austral de Chile), plots were fertilized with $80 \mathrm{~kg} \mathrm{~K}_{2} \mathrm{O} \mathrm{ha}^{-1}$ and 150 $\mathrm{kg} \mathrm{P}_{2} \mathrm{O}_{5} \mathrm{ha}^{-1}$ at sowing and with $200 \mathrm{~kg} \mathrm{~N}^{-1}$ split into three applications, $80 \mathrm{~kg} \mathrm{~N} \mathrm{ha}^{-1}$ at sowing; $60 \mathrm{~kg} \mathrm{~N}$ ha $^{-1}$ at tillering, and $60 \mathrm{~kg} \mathrm{~N} \mathrm{ha}^{-1}$ at stem elongation initiation in Experiments 1 and 2. In Experiment 3, $60 \mathrm{~kg} \mathrm{~K}_{2} \mathrm{O} \mathrm{ha}^{-1}$ and $220 \mathrm{~kg} \mathrm{P}_{2} \mathrm{O}_{5} \mathrm{ha}^{-1}$ were supplied at sowing and $250 \mathrm{~kg}$ $\mathrm{N} \mathrm{ha}^{-1}$ split into two applications, 140 and $110 \mathrm{~kg} \mathrm{~N} \mathrm{ha}^{-1}$ were added at sowing and tillering, respectively.

Plots were irrigated five times during grain filling with $12.5 \mathrm{~L} \mathrm{~m}^{-2}$ to supplement rainfall $(679,310$, and $562 \mathrm{~mm}$ during the crop season in Experiments 1, 2, and 3 , respectively). Weeds were controlled by hand and mechanically in Experiments 1 and 2, whereas in Experiment 3, $35 \mathrm{~g} \mathrm{~m}^{-2}$ of dazomet was applied to prevent weeds and fungi before sowing and $1.5 \mathrm{~L} \mathrm{ha}^{-1}$ of bentazon to prevent broadleaf weeds after emergence (Em). Septoria tritici was prevented with the subsequent addition of three active ingredients (fenpropimorphkresoxim-methyl-epoxiconazole) in doses of $1.0 \mathrm{~L} \mathrm{ha}^{-1}$.

\section{Manipulation and calculation of the source-sink ratio}

Source-sink ratios were reduced by setting black nets that intercepted $90 \%$ of incident radiation at $20 \mathrm{~cm}$ above the top of the canopy covering plots in their entirety in all the experiments. Nets had little effect on air temperature as the average temperature under the nets was $1{ }^{\circ} \mathrm{C}$ lower than in controls (Sandaña et al., 2009). Aimed at reducing the source of assimilates only during the linear growth phase of the grain treatments, $\mathrm{Sh}_{\mathrm{All}}$ and $\mathrm{Sh}_{1 \mathrm{st}}$ began $\mathrm{At}+12$ d (Fischer, 1985; Savin and Slafer, 1991).

To calculate relative change of the source due to treatments, the methodology proposed by Slafer and Savin (1994) and by Borrás et al. (2004), and used in Sandaña et al. (2009) was followed. Briefly, this method considers the fraction of cumulative intercepted radiation by nets as a proportion of the entire cumulative intercepted radiation during the grain filling period. The values of grain filling duration between anthesis and physiological maturity
(PM) and the cumulative intercepted photosynthetically

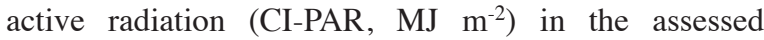
treatments are shown in Table 1.

\section{Phenological, crop, and grain measurements and calculations}

Phenological stages were recorded in experiments using the scale proposed by Zadoks et al. (1974). Grain filling duration was calculated in thermal time units $\left({ }^{\circ} \mathrm{C} \mathrm{d}\right.$ as in Monteith, 1984) at a base temperature of $0{ }^{\circ} \mathrm{C}$ as in previous studies (Hay and Kirby, 1991; Slafer et al., 1994). Thermal time was estimated as the sum of daily average temperature ([maximum temperature + minimum temperature]/2) between At-PM.

In the three experiments the time course of grain DM and water dynamics was followed after anthesis by measuring fresh and dry weights by sampling plots twice a week from At-PM. Grains from positions $1\left(\mathrm{G}_{1}\right), 2\left(\mathrm{G}_{2}\right)$, and $3\left(\mathrm{G}_{3}\right)$ of two central spikelets of two spikes per plot were sampled; $\mathrm{G}_{1}, \mathrm{G}_{2}$ and $\mathrm{G}_{3}$ were named considering the closest and furthest distance to the rachis, respectively. All these grains were measured to evaluate grain weight of individual positions of central spikelets (IGW) and stabilized grain water content (SGWC).

To standardize the timing of sampling, grains were harvested at noon $(12: 00 \mathrm{~h})$ during the entire grain filling period. The follow-up of fresh weight of grain samples (GFW) was measured immediately after harvest and IGW was quantified after drying samples for $48 \mathrm{~h}$ at $60{ }^{\circ} \mathrm{C}$. IGW was calculated using a bilinear model $\left(0.80 \geq \mathrm{r}^{2} \geq 0.99\right)$ subjected to boundary conditions (i.e. GW is described by two equations with one break point) as in Calderini et al. (1999). Grain filling durations (GFD in ${ }^{\circ} \mathrm{C} \mathrm{d}$ and days) were calculated from the break point, which is the time from At-PM, and grain filling rate $\left(\mathrm{mg}^{\circ} \mathrm{C} \mathrm{d}^{-1}, \mathrm{GFR}\right)$ was estimated from the regression slopes (Miralles et al., 1996).

To summarize the impact of source-sink treatments on grains, IGW within the spikelet was calculated as the average of all grain measured positions. In addition, the relative individual grain weight (RIGW) was calculated 
as the ratio between dry weights of grains measured at time $i$ and IGW at PM.

The dynamic of grain water concentration (relative grain water content, RGWC) and the timing when water content stabilizes (SGWC) were calculated using a trilinear model similar to that described by Pepler et al. (2006) and used by Lizana et al. (2010). The hydric plateau duration $\left({ }^{\circ} \mathrm{C} \mathrm{d}, \mathrm{HPD}\right)$ between the time when SGWC is reached and grain PM was derived from this model. Furthermore, the trilinear model delivers the SGWC used to calculate relative (\%) grain water content (RGWC on a fresh weight basis) as the ratio between absolute grain water content (AGWC) and SGWC expressed as percentage. The AGWC (mg) was calculated as the difference between grain fresh weight and individual grain dry weight (GFW - IGW). The bi- and trilinear models were fitted by using the iterative optimization routine of TBL Curve V 2.0 (Jandel Scientific, 1991).

To evaluate the relationship between IGW and SGWC for each cultivar $\times$ source-sink ratio, a two-equation regression model was used:

$\mathrm{IGW}=\alpha+\beta$ SGWC $\quad$ if $(\mathrm{SGWC} \leq \mathrm{GWC}) \quad[1]$ $\mathrm{IGW}=\alpha+\beta \mathrm{SGWC}+\beta \mathrm{GWC}$ if (SGWC $>$ GWC) [2] where $\alpha$ is the intercept $(\mathrm{mg}), \beta$ is the grain filling rate per unit of GWC decrease $\left(\mathrm{mg} \mathrm{\%} \%^{-1}\right)$, GWC is grain water content when grain reaches IGW (\%), and SGWC is stabilized grain water content (\%).

At harvest, plants from the central row of each plot were sampled in $1 \mathrm{~m}$ long of the central row of plots only in Experiments 1 and 3. After that, spikes were threshed and their grains were weighed with an analytical balance (XP205DR, Mettler Toledo, Greifensee, Switzerland) to evaluate grain yield. Dry weights were measured after drying samples at $60{ }^{\circ} \mathrm{C}$ for $48 \mathrm{~h}$. Thousand grain weight (TGW) of each sample was estimated by three random subsets of grains (100 grains each) per plot and grain number $(\mathrm{GN})$ was calculated as the ratio between grain yield and TGW. Unfortunately, the $1 \mathrm{~m}$ long plant samples were not taken at PM in Experiment 2 to avoid biased results due to bird damage.

\section{Statistical analyses and transformations}

ANOVA was performed on the experiments within each cultivar and source-sink ratio. Differences in TGW, IGW, SGWC, GFR, GFD, and HPD among source-sink ratios within each crop and experiment were compared using a Tukey test. In order to carry out a statistical analysis of the relative changes in yield, GN and TGW, these values were transformed by $\arcsin \sqrt{ }(\%) / 100$ (Sokal and Rohlf, 1995).

\section{RESULTS}

Environmental conditions and crop phenology in Experiments 1, 2, and 3

Similar climatic conditions were registered in the experiments between emergence and At (12, 15, and 13
${ }^{\circ} \mathrm{C}$, and 7, 10, and $9 \mathrm{MJ} \mathrm{m}^{-2} \mathrm{~d}^{-1}$ in Experiments 1, 2, and 3 , respectively) and during At-PM (16, 18 and $17{ }^{\circ} \mathrm{C}$, and 11,12 , and $12 \mathrm{MJ} \mathrm{m}^{-2} \mathrm{~d}^{-1}$ in Experiments 1, 2, and 3 , respectively). The control plots of cultivars showed similar phenology, anthesis dates were reached at 86 , 58, and $73 \mathrm{~d}$ after emergence in Experiments 1, 2, and 3, respectively, averaged across the cultivars (Figure 1). The grain filling period lasted for 52 and $37 \mathrm{~d}$ in 'Otto Baer' and 'Huayún-INIA', respectively in Experiment 1, while $44 \mathrm{~d}$ were recorded in Experiments 2 and 3 (Figure 1 and Table 1).

Duration of shading treatments both in days and thermal time units are shown in Table 1. In the $\mathrm{Sh}_{\text {All }}$ treatment, black nets covered the plots between $61 \%$ and $78 \%$ of the grain filling period in the control treatment of 'Otto Baer' and between 65\% and 77\% in 'Huayún-INIA' (Table 1). When thermal time units were used instead of days, these treatments showed similar durations (Table 1). The $\mathrm{Sh}_{1 \mathrm{st}}$ treatment was imposed between $33 \%$ and $39 \%$ of days relative to the control in 'Otto Baer' and between $30 \%$ and $43 \%$ in 'Huayún-INIA'. In thermal time units, the $\mathrm{Sh}_{1 \mathrm{st}}$ treatment accounted for $32 \%$ in Experiment 1 and 38\% in Experiments 2 and 3 averaged across both cultivars regarding their similar phenology (Table 1). In $\mathrm{Sh}_{2 n d}$, the relative period of source reduction was similar in days and thermal time units (i.e. between $30 \%$ and $41 \%$ of the grain filling period across cultivars) to $\mathrm{Sh}_{1 \text { st }}$ (Table 1).

Cumulative intercepted radiation (CI-PAR) during grain filling was similar between cultivars in the control treatments except in 'Huayún-INIA' during the Experiment 1 as this cultivar reached PM earlier than 'Otto Baer' (Table 1). The $\mathrm{Sh}_{\text {All }}$ treatment decreased (CI-PAR) between 55\% and 69\% relative to the control in both cultivars and across the experiments, taking into account that the nets were set at At $+12 \mathrm{~d}$. The $\mathrm{Sh}_{1 \mathrm{st}}$ and the $\mathrm{Sh}_{2 \mathrm{nd}}$ treatments reduced this variable to a similar extent, i.e. between $30 \%$ and $33 \%$ relative to the controls, respectively, across cultivars and experiments (Table 1).

Effect of the source-sink ratio on grain yield, grain number, and thousand grain weights

When plant samples were harvested at PM, i.e. in Experiments 1 and 3, grain yield of controls ranged from 1025 to $1243 \mathrm{~g} \mathrm{~m}^{-2}$ ('Otto Baer' from 1025 to $1177 \mathrm{~g} \mathrm{~m}^{-2}$ and 'Huayún-INIA' from 1243 to $1035 \mathrm{~g} \mathrm{~m}^{-2}$ in Experiments 1 and 3, respectively). The sensitivity of grain yield depended on the source-sink treatment $(\mathrm{p} \leq 0.001)$ as $\mathrm{Sh}_{\mathrm{All}}$ was the treatment with the greatest impact (52\% of grain yield reduction), followed by $\mathrm{Sh}_{1 \mathrm{st}}(29 \%)$ and the least impact was found under $\mathrm{Sh}_{2 n d}(23 \%)$, averaged across cultivars and experiments (Figure 2). These responses were consistent across cultivars taking into account that no interactions among cultivars, experiments or sourcesink treatments were found ( $\mathrm{p} \geq 0.05)$; however, 'Otto 

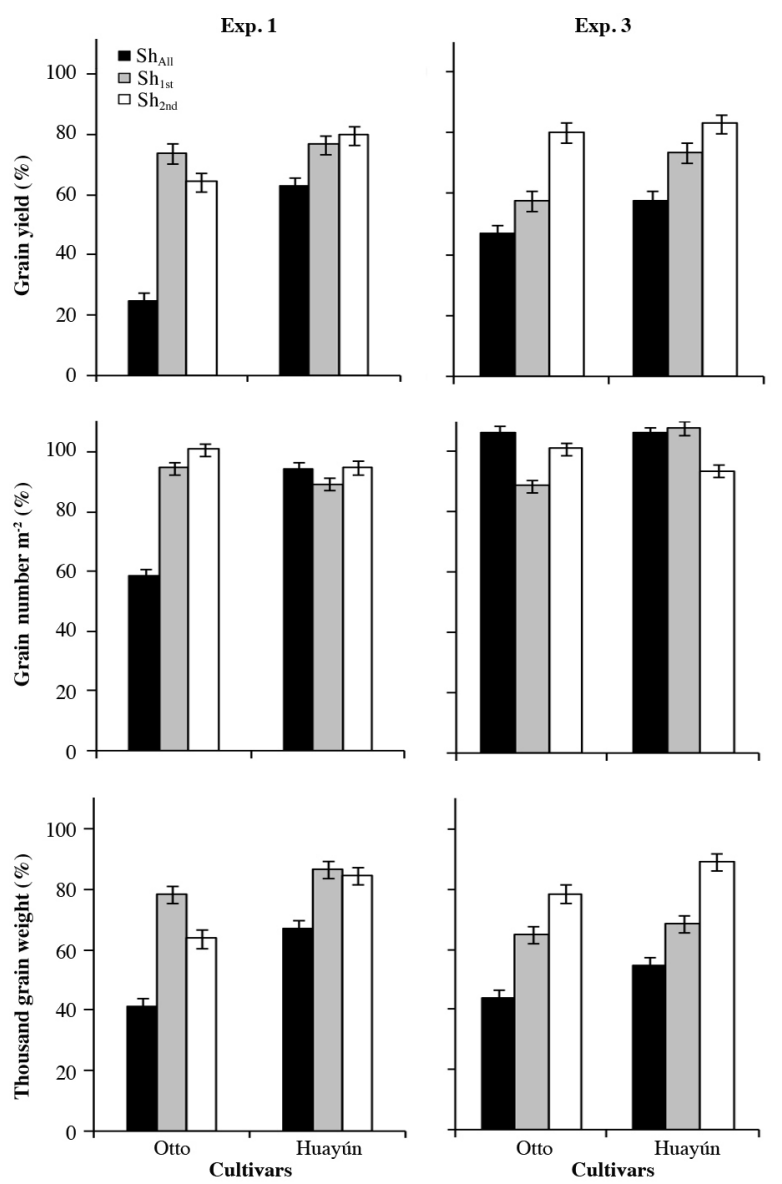

Vertical bars show the standard error of the mean.

Figure 2. Relative grain yield, grain number, and thousand grain weights of source-sink reduction treatments shown as a percentage of those traits recorded in control treatment of wheat 'Otto Baer' and 'Huayún-INIA' at harvest. Source-sink reduction treatments were assessed during the entire ( $\mathrm{Sh}_{\mathrm{All}}$, closed bars), first half $\left(\mathrm{Sh}_{1 \mathrm{st}}\right.$, grey bars), and second half ( $\mathrm{Sh}_{2 \mathrm{st}}$, open bars) phases of the grain filling period in both cultivars during 2004-2005 (Experiment 1) and 20052006 (Experiment 3) growing seasons.

Baer' was more sensitive to the source shortage across the treatments $\left(65 \%, 34 \%\right.$, and $28 \%$ in $\mathrm{Sh}_{\mathrm{All}}, \mathrm{Sh}_{1 \mathrm{st}}$ and $\mathrm{Sh}_{2 \text { nd }}$ treatment, respectively) than 'Huayún-INIA' (40\%, 25\%, and $19 \%$ in $\mathrm{Sh}_{\mathrm{All}}, \mathrm{Sh}_{1 \mathrm{st}}$ and $\mathrm{Sh}_{2 \mathrm{nd}}$ treatment, respectively), across Experiments 1 and 3 (Figure 2).

The GN of control treatments averaged across cultivars was 23229 and $30930 \mathrm{~m}^{-2}$ in Experiments 1 and 3, respectively. The $\mathrm{Sh}_{\text {All }}$ treatment reduced GN of 'Otto Baer' by $41 \%$ in Experiment 1 even though the nets were set At +12 d to avoid negative impacts on grain number. As expected, GN of 'Otto Baer' in Experiment 3 and 'Huayún-INIA' in both experiments were not sensitive to source reduction (Figure 2). Consistent with these results, treatments $\mathrm{Sh}_{1 \mathrm{st}}$ and $\mathrm{Sh}_{2 \text { nd }}$ had little impact on $\mathrm{GN}$ of cultivars (Figure 2).

Grain yield recorded in the source-sink treatments was mainly explained by TGW since a linear association was found between these traits $\left(\mathrm{R}^{2}=0.60, \mathrm{p} \leq 0.001\right)$ including the commented exception of 'Otto Baer' under $\mathrm{Sh}_{\mathrm{All}}$ in Experiment 1. Control treatments reached higher TGW ( $\mathrm{p} \leq 0.001)$ in Experiment 1 (47 g) than in Experiment 3 (37 g). Between cultivars, differences in TGW ( $\mathrm{p} \leq$ 0.05 ) were found in both experiments, where 'Otto Baer' reached TGW of 45 and $39 \mathrm{~g}$, while 'Huayún-INIA' reached 50 and $35 \mathrm{~g}$ in Experiments 1 and 3, respectively. Similar to grain yield, the effect of source reduction on TGW by $\mathrm{Sh}_{\text {All }}$ showed the greatest impact ( $48 \%$ averaged across cultivars and experiments), whereas $\mathrm{Sh}_{1 \mathrm{st}}$ and $\mathrm{Sh}_{2 \text { nd }}$ had lower effect $(26 \%$ and $22 \%$, respectively, averaged across cultivars and experiments). In the $\mathrm{Sh}_{\mathrm{All}}$ treatment, 'Otto Baer' was more sensitive (58\%) than 'HuayúnINIA' $(39 \%)$ when the source reduction treatments were averaged across experiments (Figure 2). The $\mathrm{Sh}_{1 \mathrm{st}}$ treatment decreased TGW by $29 \%$ and $23 \%$ in 'Otto Baer' and 'Huayún-INIA', respectively, while $\mathrm{Sh}_{2 n d}$ had a similar or lower impact depending on the cultivar, i.e. $30 \%$ and $14 \%$ in 'Otto Baer' and 'Huayún-INIA', respectively (Figure 2).

\section{Individual grain weight and water content responses to source reduction}

Grain weight and water dynamics were measured at each grain position of the central spikelets showing similar behavior (data not shown). To facilitate the view of data of individual grains, DM and water dynamics as well as their relationships are shown averaged across grain weight of individual positions of central spikelets $\left(G_{1}, G_{2}\right.$, and $G_{3}$, hereafter named IGW). Source-sink treatments decreased ( $\mathrm{p} \leq 0.001$ ) IGW in both cultivars (Table 2) but, similarly to TGW, no interaction ( $\mathrm{p} \geq 0.05$ ) between cultivar and the source-sink ratios was found. Thus, $\mathrm{Sh}_{\mathrm{All}}$ (the most influential source-sink treatment) decreased IGW by $57 \%$ in 'Otto Baer' and $48 \%$ in 'Huayún-INIA' averaged across experiments. These results confirm, in turn, the high sensitivity of wheat under strong source shortage (Table 2 , Figure 3 ). The negative effect of $\mathrm{Sh}_{\text {All }}$ on IGW was due to both the lower $(\mathrm{p} \leq 0.001)$ grain filling rate and the shorter ( $\mathrm{p} \leq 0.001)$ duration of grain filling shown by both cultivars (Table 2, Figure 3).

When the crop was shaded during the first half of the grain filling period $\left(\mathrm{Sh}_{1 \mathrm{st}}\right)$ the impact on IGW was higher $(33 \%)$ than in the second half $\left(\mathrm{Sh}_{2 \mathrm{nd}}\right)$ as IGW decreased by $12 \%$. Under $\mathrm{Sh}_{1 \mathrm{st}}$, 'Otto Baer' was also more sensitive than 'Huayún-INIA' since IGW decreased by $37 \%$ and $28 \%$, respectively, averaged across experiments (Table 2 , Figure 3). However, and more important, grains of both cultivars under $\mathrm{Sh}_{1 \mathrm{st}}$ were able to continue their growth after the nets were removed from the plots (Figure 3). It is important to highlight that there were different magnitudes of IGW change between experiments after the $\mathrm{Sh}_{1 \mathrm{st}}$ treatment ended. The removal of nets in $\mathrm{Sh}_{1 \mathrm{st}}$ was earlier in Experiment 1 than in Experiments 2 and 3 (Figure 3), i.e. in Experiment 1 'Otto Baer' and 'Huayún- 
Table 2. Grain weight of individual positions of central spikelets (IGW), grain filling duration (GFD), and grain filling rate (GFR) of wheat 'Otto Baer' and 'Huayún-INIA' under control and source-sink reduction treatments $\left(\mathrm{S}_{-} \mathbf{S r}_{\text {atios }}\right)$ during the entire $\left(\mathrm{Sh}_{\mathrm{All}}\right)$, first-half $\left(\mathrm{Sh}_{1 \mathrm{st}}\right)$ and second-half $\left(\mathrm{Sh}_{2 \mathrm{st}}\right)$ periods in the 2004-2005 (Experiments 1 and 2) and 2005-2006 (Experiment 3) growing seasons.

\begin{tabular}{|c|c|c|c|c|c|c|c|c|c|c|}
\hline \multirow[b]{2}{*}{ Cultivar } & \multirow[b]{2}{*}{ S-S $\mathrm{S}_{\text {ratios }}$} & \multicolumn{3}{|c|}{ Individual grain weight $(\mathrm{mg}, \%)$} & \multicolumn{3}{|c|}{ Grain filling duration $\left({ }^{\circ} \mathrm{C} \mathrm{d}\right)$} & \multicolumn{3}{|c|}{ Grain filling rate $\left(\mathrm{mg}^{\circ} \mathrm{C} \mathrm{d}^{-1}\right)$} \\
\hline & & Exp. 1 & Exp. 2 & Exp. 3 & Exp. 1 & Exp. 2 & Exp. 3 & Exp. 1 & Exp. 2 & Exp. 3 \\
\hline \multirow[t]{4}{*}{ Otto Baer } & Control & 51.0 & 41.8 & 47.8 & 837 & 747 & 839 & 0.079 & 0.070 & 0.060 \\
\hline & $\mathrm{Sh}_{\mathrm{All}}$ & $17.4(-66)$ & $22.7(-46)$ & $19.3(-59)$ & 592 & 606 & 573 & 0.036 & 0.044 & 0.034 \\
\hline & $\mathrm{Sh}_{1 \mathrm{st}}$ & $37.7(-27)$ & $26.7(-36)$ & $24.4(-49)$ & 809 & 708 & 667 & 0.062 & 0.043 & 0.039 \\
\hline & $\mathrm{Sh}_{2 \mathrm{nd}}$ & $34.4(-33)$ & $44.0(5)$ & $40.8(-14)$ & 699 & 800 & 819 & 0.065 & 0.064 & 0.049 \\
\hline \multirow[t]{4}{*}{ Huayún-INIA } & Control & 58.4 & 56.8 & 46.2 & 605 & 727 & 768 & 0.120 & 0.100 & 0.065 \\
\hline & $\mathrm{Sh}_{\mathrm{All}}$ & $29.3(-50)$ & $33.9(-40)$ & $21.4(-54)$ & 531 & 680 & 570 & 0.058 & 0.059 & 0.037 \\
\hline & $\mathrm{Sh}_{1 \mathrm{st}}$ & $50.7(-13)$ & $40.4(-29)$ & $27.2(-41)$ & 699 & 724 & 840 & 0.083 & 0.069 & 0.030 \\
\hline & $\mathrm{Sh}_{2 \mathrm{nd}}$ & $47.4(-18)$ & $56.5(-1)$ & $41.0(-11)$ & 581 & 722 & 706 & 0.095 & 0.099 & 0.062 \\
\hline sem & & & 1.5 & & & 12 & & & 0.003 & \\
\hline $\mathrm{E}$ & & & $* * *$ & & & $* *$ & & & $* * *$ & \\
\hline $\mathrm{Cv}$ & & & $* * *$ & & & $* *$ & & & $* * *$ & \\
\hline S-S & & & $* * *$ & & & $* * *$ & & & $* * *$ & \\
\hline $\mathrm{E} \times \mathrm{Cv}$ & & & $* * *$ & & & $* * *$ & & & $* * *$ & \\
\hline $\mathrm{E} \times \mathrm{S}-\mathrm{S}$ & & & $* * *$ & & & $* *$ & & & $* * *$ & \\
\hline $\mathrm{Cv} \times \mathrm{S}-\mathrm{S}$ & & & ns & & & $* *$ & & & $* *$ & \\
\hline $\mathrm{E} \times \mathrm{Cv} \times \mathrm{S}-\mathrm{S}$ & & & ns & & & ns & & & ns & \\
\hline
\end{tabular}

Values in parenthesis indicate percentage values $(\%)$ show grain weight decrease under the source reduction treatments relative to the controls.

$*$, **, ***Significant at $0.05,0.01$, and 0.001 probability levels, respectively.

sem: Standard error of the mean; ns: non significant; E: experiment; Cv: cultivar; S-S: source-sink ratio.

INIA' accumulated $67 \%$ and $60 \%$, respectively, of their final IGW after removing the nets in $\mathrm{Sh}_{1 \mathrm{st}}$; whereas in Experiments 2 and 3 the accumulation of IGW was lower (i.e. $31 \%$ in 'Otto Baer' and $41 \%$ in 'Huayún-INIA', averaged across Experiments 2 and 3). IGW reduction under $\mathrm{Sh}_{2 \text { nd }}$ was higher in 'Otto Baer' than in 'HuayúnINIA' across experiments; i.e. 14 and 10\%, respectively (Table 2, Figure 3).

The main driver of IGW reduction under the source-sink treatments was the grain filling rate as a linear relationship
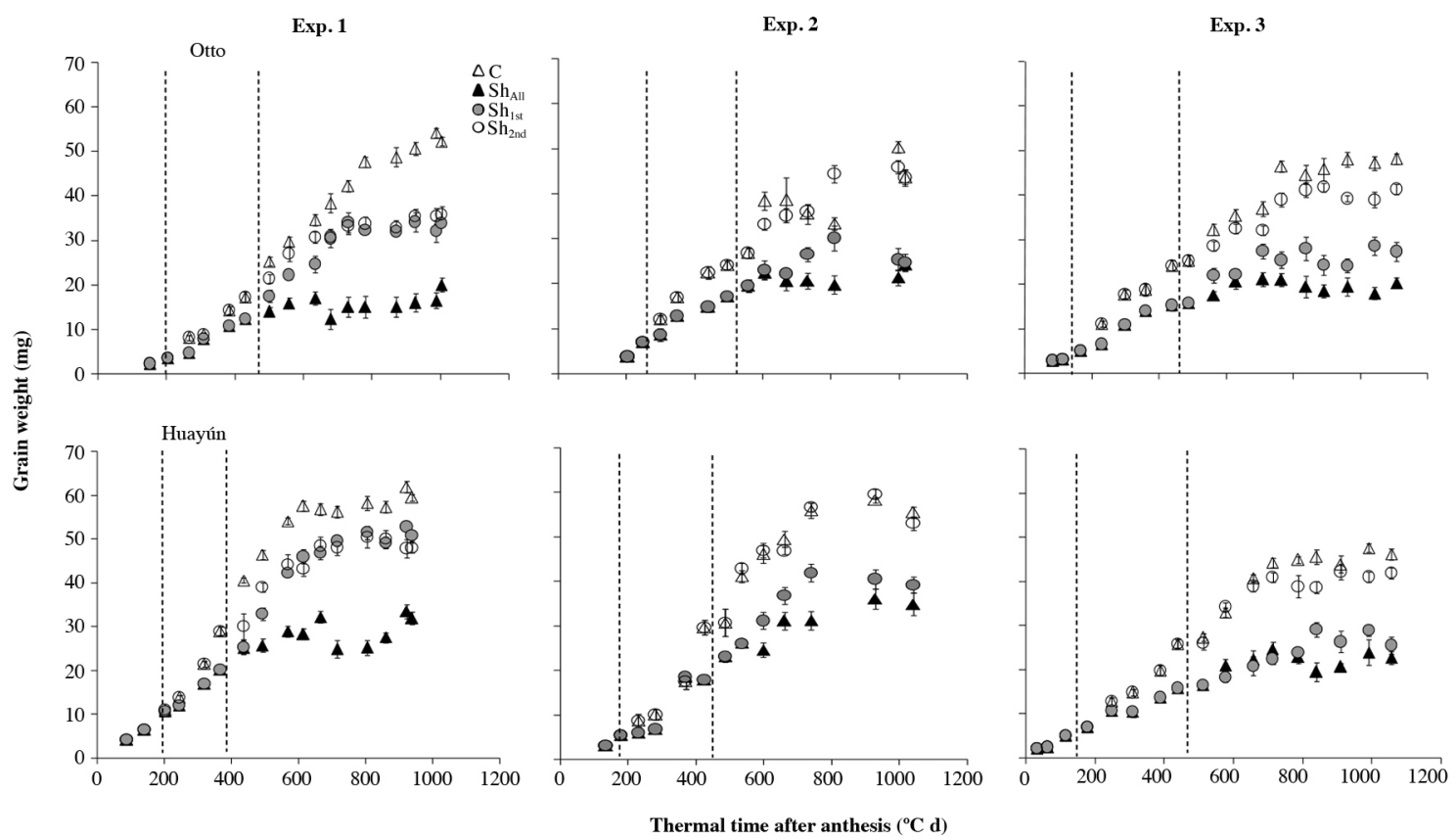

Vertical bars show the standard error of the mean. The DM dynamics of $\mathrm{C}$ and $\mathrm{Sh}_{\mathrm{All}}$ were built with data measured during the entire grain filling period in these treatments; whereas in $\mathbf{S h}_{1 \mathrm{st}}$ and $\mathrm{Sh}_{2 \text { nd }}$ data corresponding to $\mathrm{C}$ and $\mathrm{Sh}_{\mathrm{All}}$ were used until the shades were taken out or set in $\mathrm{Sh}_{1 \mathrm{st}}$ and $\mathrm{Sh}_{2 \mathrm{nd}}$, respectively. Left and right vertical lines show the start of the $\mathrm{Sh}_{1 s t}$ and $\mathrm{Sh}_{2 n d}$ treatments, respectively.

Figure 3. Time-course in thermal time units of individual grain weight (IGW) from central spikelets of wheat 'Otto Baer' and 'Huayún-INIA' under control (C, open triangles) and source-sink reduction treatments during the entire ( $\mathbf{S h}_{\mathrm{All}}$, closed triangles), first half $\left(\mathrm{Sh}_{1 \mathrm{st}}, \mathrm{gray}_{\mathrm{eircles}}\right.$ ), and second half $\left(\mathrm{Sh}_{2 \mathrm{st}}\right.$, open circles) phases of the grain filling period, during 2004-2005 (Experiments 1 and 2) and 2005-2006 (Experiment 3) growing seasons. 

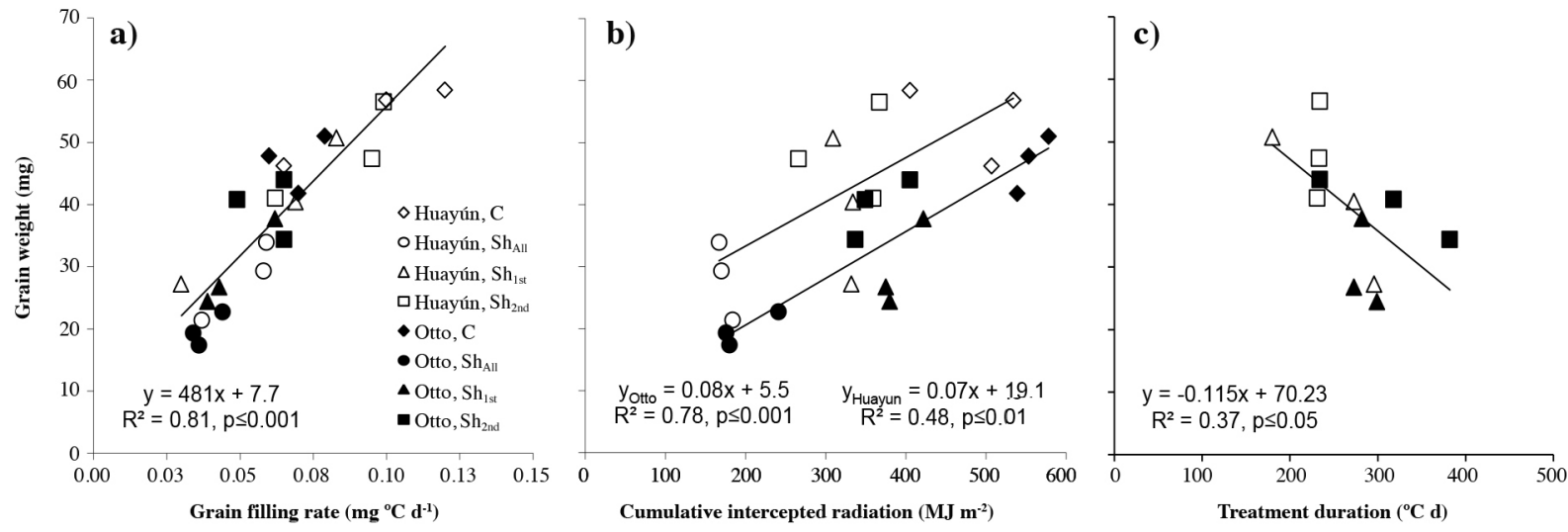

Figure 4. Relationships between individual grain weight from central spikelets and (a) grain filling rate, (b) cumulative intercepted radiation (CI-PAR), and (c) source-sink treatment duration of wheat 'Otto Baer' (black symbols) and 'Huayún-INIA' (white symbols) under control (C, diamonds) and source-sink reduction treatments during the entire ( $\mathbf{S h}_{\mathrm{All}}$, circles), first half (Sh $\mathbf{S h}_{1 \mathrm{st}}$, triangles), and second half (Sh $\mathbf{~}_{2 \mathrm{st}}$, $\mathbf{s q u a r e s )}$ phases in 2004-2005 (Experiments 1 and 2) and 2005-2006 (Experiment 3) growing seasons.

$\left(\mathrm{R}^{2}=0.81, \mathrm{p} \leq 0.001\right.$; Figure $\left.4 \mathrm{a}\right)$ was found between these variables. Conversely, IGW showed no association with grain filling duration $\left(\mathrm{R}^{2}=0.014, \mathrm{p} \geq 0.05\right)$. Interestingly, final IGW was associated with the cumulative intercepted radiation across cultivars and source-sink treatments, and partially with the length of the source-shortage treatment (Figures $4 b$ and 4c).

Similar to dry matter, grain water dynamic was also affected by the source reduction but less than GW. Thus, $\mathrm{Sh}_{\text {All }}$ decrease $(\mathrm{p} \leq 0.001)$ the SGWC $25 \%$ in 'Otto Baer' and $29 \%$ in 'Huayún-INIA' averaged across experiments (Table 3, Figure 5). The $\mathrm{Sh}_{1 \mathrm{st}}$ decreased SGWC $21 \%$ in Otto Baer and 23\% in 'Huayún-INIA'. Under this treatment, grain water dynamic was maintained even after the nets were removed (Figure 5), but unlike grain DM, SGWC was not recovered after the removal of nets (Figures 3 and 5). The lowest impact of the source-sink treatments on $\mathrm{SGWC}$ was recorded in $\mathrm{Sh}_{2 \mathrm{nd}}$, where $\mathrm{SGWC}$ decreased only $5 \%$ in both cultivars across experiments (Table 3 ) and grain water dynamics were almost not affected when compared with the control treatments (Figure 5). The source-sink treatments, cultivars and experiments affected ( $\mathrm{p} \leq 0.001$ ) the hydric plateau duration (HPD); however, no clear trends were found for HPD among cultivars and source-sink treatments (Table 3).

Remarkably, although SGWC was less sensitive to the source reductions than grain DM, a close association between final IGW and SGWC was found across cultivars, source-sink treatments and experiments (Figures 6a and 6b). SGWC was also found to be an accurate predictor of the grain filling rate as a positive association $\left(R^{2}=0.89\right.$, $\mathrm{p} \leq 0.001)$ was obtained when both traits were plotted together (Figure 6b). On the other hand, no associations were found when IGW was tried with either the grain

Table 3. Stabilized grain water content of individual positions of central spikelets (SGWC) and hydric plateau duration (HPD) of wheat 'Otto Baer' and 'Huayún-INIA' under control and source-sink reduction treatments $\left(\mathbf{S}-\mathbf{S}_{\text {ratios }}\right)$ during the entire $\left(\mathbf{S h}_{\mathrm{All}}\right)$, first-half $\left(\mathbf{S h}_{1 \mathrm{st}}\right)$, and secondhalf $\left(\mathrm{Sh}_{2 \mathrm{st}}\right)$ phases during 2004-2005 (Experiments 1 and 2) and 2005-2006 (Experiment 3) growing seasons.

\begin{tabular}{|c|c|c|c|c|c|c|c|}
\hline \multirow[b]{2}{*}{ Cultivar } & \multirow[b]{2}{*}{$\mathrm{S}-\mathrm{S}_{\text {ratios }}$} & \multicolumn{3}{|c|}{ Stabilized grain water content $(\mathrm{mg}, \%)$} & \multicolumn{3}{|c|}{ Hydric plateau duration $\left({ }^{\circ} \mathrm{C}\right.$ d) } \\
\hline & & Exp. 1 & Exp. 2 & Exp. 3 & Exp. 1 & Exp. 2 & Exp. 3 \\
\hline \multirow[t]{4}{*}{ Otto Baer } & Control & 37.0 & 37.1 & 33.3 & 424 & 357 & 554 \\
\hline & $\mathrm{Sh}_{\mathrm{All}}$ & $27.1(-27)$ & $28.5(-23)$ & $25.3(-24)$ & 261 & 342 & 355 \\
\hline & $\mathrm{Sh}_{1 \mathrm{st}}$ & $30.1(-19)$ & $27.9(-25)$ & $26.7(-20)$ & 474 & 483 & 412 \\
\hline & $\mathrm{Sh}_{2 \mathrm{nd}}$ & $31.8(-14)$ & $35.7 \quad(-4)$ & $31.9(-4)$ & 346 & 402 & 524 \\
\hline \multirow[t]{4}{*}{ Huayún-INIA } & Control & 44.5 & 40.2 & 30.7 & 274 & 272 & 415 \\
\hline & $\mathrm{Sh}_{\mathrm{All}}$ & $31.3(-30)$ & $28.2(-30)$ & $22.4(-27)$ & 235 & 316 & 406 \\
\hline & $\mathrm{Sh}_{1 \mathrm{st}}$ & $35.0(-21)$ & $33.0(-18)$ & $21.4(-29)$ & 375 & 297 & 556 \\
\hline & $\mathrm{Sh}_{2 \mathrm{nd}}$ & $39.0(-12)$ & $42.1 \quad(5)$ & $29.9(-3)$ & 304 & 252 & 399 \\
\hline sem & & & 0.7 & & & 12 & \\
\hline $\mathrm{E}$ & & & $* * *$ & & & $* * *$ & \\
\hline $\mathrm{Cv}$ & & & $* * *$ & & & $* * *$ & \\
\hline S-S & & & $* * *$ & & & $* * *$ & \\
\hline $\mathrm{E} \times \mathrm{Cv}$ & & & $* * *$ & & & $*$ & \\
\hline $\mathrm{E} \times \mathrm{S}-\mathrm{S}$ & & & $* * *$ & & & $*$ & \\
\hline $\mathrm{Cv} \times \mathrm{S}-\mathrm{S}$ & & & $*$ & & & $* *$ & \\
\hline $\mathrm{E} \times \mathrm{Cv} \times \mathrm{S}-\mathrm{S}$ & & & ns & & & $* *$ & \\
\hline
\end{tabular}

Values in parenthesis indicate percentage values (\%) show grain weight decrease under the source reduction treatments relative to the controls.

$*, * *, * * *$ Significant at $0.05,0.01$, and 0.001 probability levels, respectively.

sem: Standard error of the mean; ns: non-significant; E: experiment; Cv: cultivar; S-S: source-sink ratio. 


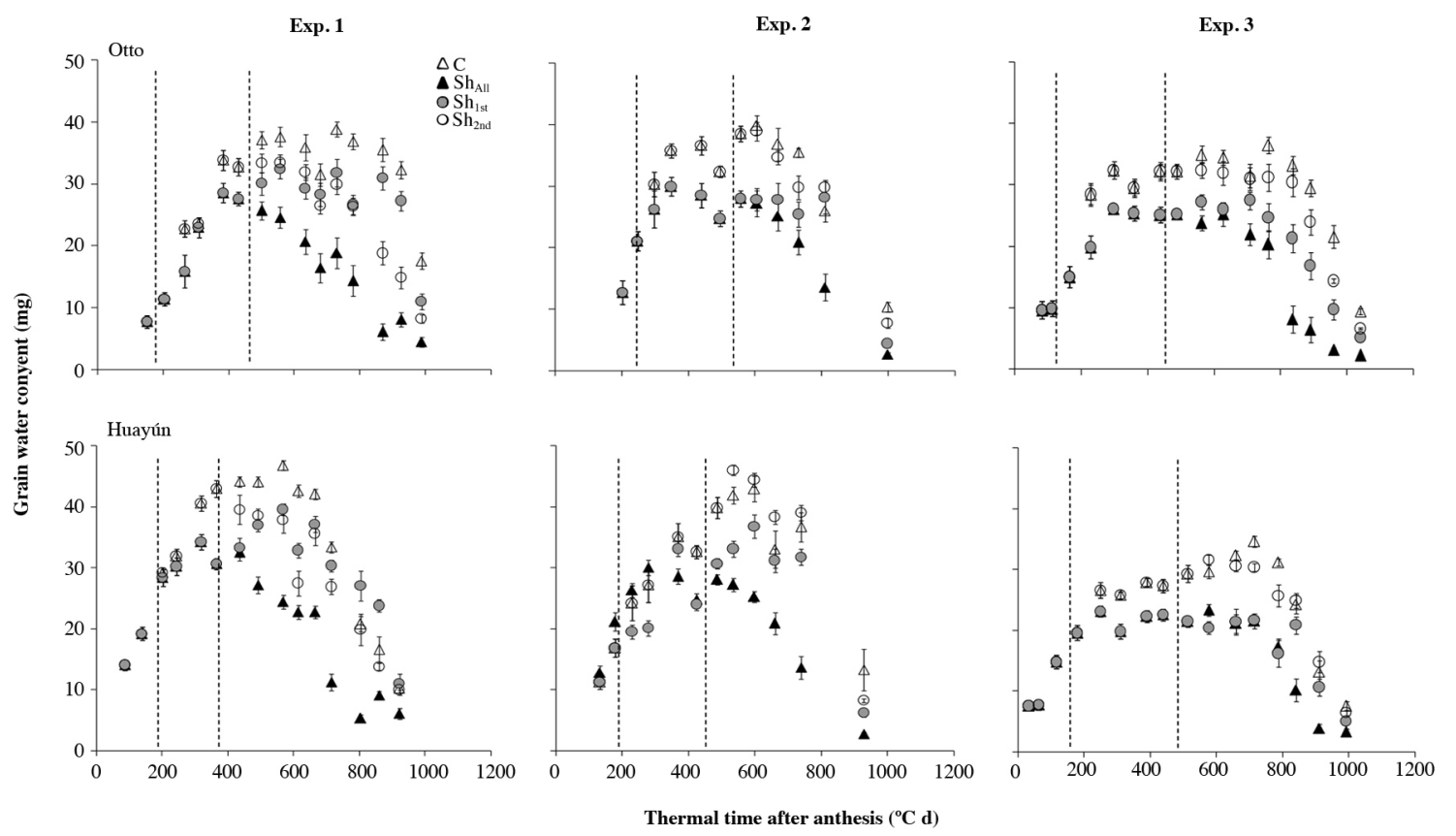

Left and right vertical lines show start of $\mathrm{Sh}_{1 \mathrm{st}}$ and $\mathrm{Sh}_{2 \text { nd }}$ treatments, respectively.

Figure 5. Time-course in thermal time units of individual grain water content (GWC) from central spikelets of wheat 'Otto Baer' and 'HuayúnINIA' under control (C, open triangles) and source-sink reduction treatments during the entire $\left(\mathbf{S h}_{\mathrm{All}}\right.$, closed triangles), first half $\left(\mathbf{S h}_{1 \mathrm{st}}\right.$, gray circles), and second half ( $\mathrm{Sh}_{2 \mathrm{st}}$, open circles) phases of the grain filling period, during 2004-2005 (Experiments 1 and 2 ) and 2005-2006 (Experiment 3) growing seasons. Vertical bars show the standard error of the mean. The water dynamics of $\mathrm{C}$ and $\mathrm{Sh}_{\mathrm{All}} \mathrm{were}_{\mathrm{built}}$ with data measured during the entire grain filling period in these treatments; whereas in $\mathbf{S h}_{1 \mathrm{st}}$ and $\mathbf{S h}_{2 \text { nd }}$ data corresponding to $\mathbf{C}$ and $\mathbf{S h} \mathbf{A l l}_{\mathrm{All}}$ were used until the shades were taken out or set in $\mathrm{Sh}_{1 \mathrm{st}}$ and $\mathrm{Sh}_{2 \mathrm{nd}}$, respectively.

filling duration $\left(\mathrm{R}^{2}=0.13, \mathrm{p} \geq 0.05\right)$ or the hydric plateau duration $\left(\mathrm{R}^{2}=0.18, \mathrm{p} \geq 0.05\right)$.

\section{DISCUSSION}

The evaluation of wheat response to different sourcesink ratios has been widely attempted and it is generally accepted that this crop is scarcely limited by the source of assimilates during grain filling (Slafer and Savin, 1994; Borrás et al., 2004). However, in a previous experiment assessing only 'Otto Baer', greater sensitivity than expected was found when this cultivar was exposed to a severe source reduction (Sandaña et al., 2009). Therefore, the present study aimed to evaluate simultaneously the sensitivity of two wheat cultivars to strong source reductions during grain filling and to improve the understanding of the causes associated with the greaterthan-expected sensitivity of grain weight found previously (Sandaña et al., 2009). Moreover, two additional questions of the present study previously unexplored to wheat were: (i) whether the wheat sensitivity to source reduction depends on the time at which the source-sink ratio occurs and (ii) whether differences in grain weight in response to the source shortage are associated with grain water dynamics as was reported for maize (Borrás et al., 2003).

In the present study the assimilate availability of wheat was reduced by $65 \%, 33 \%$, and $33 \%$ across experiments for $\mathrm{Sh}_{\mathrm{All}}, \mathrm{Sh}_{1 \mathrm{st}}$, and $\mathrm{Sh}_{2 \mathrm{nd}}$, respectively, following the quantification proposed by Slafer and Savin (1994) and Borrás et al. (2004). These source reductions were similar to those carried out in previous assessments of wheat where the calculated assimilate availability per grain was decreased by up to $70 \%$ (Borrás et al., 2004).

Under the $\mathrm{Sh}_{\mathrm{All}}$ treatment, TGW and IGW reductions across cultivars and experiments were $48 \%$ and 53\%, respectively (Figures 2 and 3 , and Table 2). The sensitivity of TGW and IGW found in the present study confirms previous findings that under very high source reduction wheat grain weight decreases to a greater extent than generally reported (up to $32 \%$, Borrás et al., 2004). By contrast, Beed et al. (2007) found decreases of TGW by only $27 \%$ when the source was reduced by setting nets intercepting $80 \%$ of incident radiation from two weeks (i.e. 14 d) after At until PM (i.e. 27 d).

Differences between the present study and that of Beed et al. (2007) could be ascribed to different water soluble carbohydrates (WSC) stored in the stems by the crops as genetic variability has been found in wheat (Ehdaie et al., 2008; Dreccer et al., 2009) and the demand by grains, which would explain differences between 'Otto Baer' and 'Huayún-INIA'. This is consistent with that shown by Serrago et al. (2013) where the mobilization of reserves from stems was an important source of assimilates for growing grains in wheat and barley. Indeed, increases in 

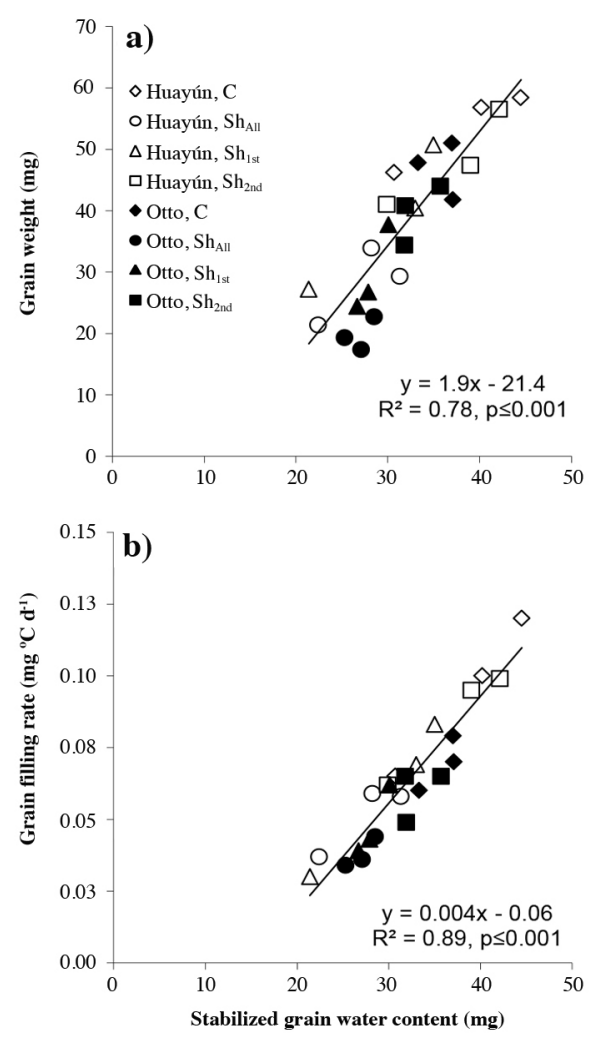

Figure 6. Relationship between individual grain weight (a) or grain filling rate (b) and the stabilized grain water content of wheat cvs. Otto Baer (closed symbols) and Huayún-INIA (open symbols) under control ( $\mathrm{C}$, diamonds) and source-sink reduction treatments during the entire $\left(\mathrm{Sh}_{\mathrm{All}}\right.$, circles), first half ( $\mathrm{Sh}_{1 \mathrm{st}}$, triangles) and second half $\left(\mathrm{Sh}_{2 \mathrm{st}}\right.$, squares) phases of the grain filling period during the 2004 2005 (Experiments 1 and 2) and 2005-2006 (Experiment 3) growing seasons.

WSC supply to grain yield and TGW have been reported for wheat cultivars released in the UK from 1972 to 1995 (Foulkes et al., 2002; Shearman et al., 2005). In addition, Beed et al. (2007) evaluated winter wheat cultivars, while in our study spring cultivars with a shorter crop cycle were investigated, i.e. $72 \mathrm{~d}$ from emergence to anthesis averaged across cultivars and growing seasons (Figure 1). Likely, spring wheats could accumulate fewer soluble carbohydrates up to anthesis. Therefore, the sensitivity of grain yield to high source shortage during the grain filling of spring cultivars in high-yield environments seems to respond similar to maize as Sala et al. (2007) found grain weight reductions by $55 \%$ and $62 \%$ when $85 \%$ and $100 \%$ leaves were removed at $20 \mathrm{~d}$ after silking, respectively. However, in wheat the spike photosynthesis could be an important source of assimilates to the grains as was found by Serrago et al. (2013) when these organs were not shadowed.

Shading imposed during the $\mathrm{Sh}_{1 \mathrm{st}}$ treatment strongly affected IGW. In $\mathrm{Sh}_{1 \text { st }}$, both cultivars showed reductions of $26 \%$ in TGW, while IGW decreased from $13 \%$ to $49 \%$.
The $\mathrm{Sh}_{2 \text { nd }}$ treatment had lower impact on both TGW (i.e. $22 \%$ decreases) and IGW (12\%), although the latter trait showed a wide range of reduction, i.e. between $5 \%$ and $33 \%$. Our results support that source reduction earlier in grain filling has higher impact on final grain weight and yield than later ones, thus confirming the hypothesis of Borrás et al. (2004).

The IGW was positively associated with grain filling rate across all source-sink treatments, which is consistent with previous studies where grain weight has been found to be closely related with the grain filling rate (Chowdhury and Wardlaw, 1978; Calderini et al., 1999; Sandaña et al., 2009; Serrago et al., 2013). Nevertheless, no association was found between IGW and grain filling duration; however, the source-sink treatments reduced ( $\mathrm{p} \leq 0.001$ ) grain filling and in turn decreased cumulative intercepted radiation available for plants. For this reason, the effect of grain filling duration on IGW cannot be completely discounted. In addition, cumulative intercepted radiation was more descriptive of the IGW sensitivity than the treatment duration (Figures $4 \mathrm{~b}$ and $4 \mathrm{c}$ ). The latter is in line with the source limitation to the growing grains found in the present experiment.

The sensitivity of SGWC under source-sink treatments was lower than that of IGW. This contrasting sensitivity is in agreement with that found by Sala et al. (2007) in maize (TGW decreased 59\%, while GWC 15\%) and contrary to the response reported by Borrás et al. (2003) for the same crop, where the maximum water content was more sensitive (33\% reduction) than grain weight $(22 \%$ reduction). Despite different sensitivities found between dry matter and water in our study, both dry matter and maximum grain water content correlated strongly, as in maize (Borrás et al., 2003; Sala et al., 2007).

The IGW showed recovery ability by continuing their growth after the nets were removed in the $\mathrm{Sh}_{1 \mathrm{st}}$ treatment, though this trait attained a lower value than the control, possibly due to SGWC being achieved earlier in the grain filling period, thus confirming the hypothesis of Borrás et al. (2004) that source reduction at the beginning of grain growth decreases the maximum water content of grains, thereby determining a lower sink size.

The dry matter and water dynamics of grains are not independent each other in crops like wheat, maize and sunflower (Rondanini et al., 2009). The present study demonstrate that the relationship between dry matter and water content of grains is maintained even when the source-sink ratio was decreased either early $\left(\mathrm{Sh}_{\mathrm{All}}\right.$ and $\left.\mathrm{Sh}_{1 \mathrm{st}}\right)$ and later $\left(\mathrm{Sh}_{2 \mathrm{nd}}\right)$ in the grain filling period.

\section{CONCLUSION}

In wheat grain yield and grain weight showed a high response to reduced source-sink ratios under the assessed conditions of this study, i.e. very high decreased 
assimilate availability evaluated in a high yield potential environment. Grain yield penalties were mainly due to the sensitivity of IGW. IGW sensitivity to source reduction varied according to the length of the treatment and the timing of setting, i.e. high, moderate and mild impact were found in $\mathrm{Sh}_{\mathrm{All}}, \mathrm{Sh}_{1 \mathrm{st}}$ and $\mathrm{Sh}_{2 \mathrm{nd}}$ treatments, respectively. This is particularly important because wheat sensitivity to source reduction during grain filling could be higher than previously reported. Cultivars assessed in this study were able to increase IGW when assimilate availability was enhanced during the second half of grain filling; however, IGW was highly decreased compared with the controls. Importantly, the stabilized grain water content was found to be a good estimator of the final IGW across the sourcesink treatments and seasons assessed.

\section{ACKNOWLEDGEMENTS}

This study was funded by Fundación Andes, Project C-13855 (8). Fortalecimiento de la Docencia e Investigación en Universidades Regionales competitive grant. C.I. Harcha held a postgraduate scholarship from Fundación Andes. We are very grateful to Dr. Claudio Jobet from Instituto de Investigaciones Agropecuarias, INIA-Carillanca, Chile, for providing seed of the two wheat cultivars used in this study. We also thanks Luis Vargas (R.I.P.); Universidad Austral de Chile, for technical assistance during the field experiments and to Helen Lowry for revising the English usage.

\section{LITERATURE CITED}

Beed, F.D., N.D. Paveley, and R. Sylvester-Bradley. 2007. Predictability of wheat growth and yield in light-limited conditions. Journal of Agricultural Science 145:63-79.

Borrás, L., G.A. Slafer, and M.E. Otegui. 2004. Seed dry weight response to source-sink manipulations in wheat, maize and soybean: a quantitative reappraisal. Field Crops Research 86:131146.

Borrás, L., and M.E. Westgate. 2006. Predicting maize kernel sink capacity early in development. Field Crops Research 95:223-233.

Borrás, L., M.E. Westgate, and M.E. Otegui. 2003. Control of kernel weight and kernel water relations by post-flowering source-sink ratio in maize. Annals of Botany 91:857-867.

Calderini, D.F., L.G. Abeledo, R. Savin, and G.A. Slafer. 1999. Effect of temperature and carpel size during pre-anthesis on potential grain weight in wheat. Journal of Agricultural Science 132:453-459.

Calderini, D.F., L.G. Abeledo, and G.A. Slafer. 2000. Physiological maturity in wheat based on kernel water and dry matter. Agronomy Journal 92:895-901.

Calderini, D.F., M.P. Reynolds, and G.A. Slafer. 2006. Source-sink effects on grain weight of bread wheat, durum wheat, and triticale at different locations. Australian Journal of Agricultural Research 57:227-233.

Chowdhury, S.I., and I. Wardlaw. 1978. The effects of temperature on kernel development in cereals. Australian Journal of Agricultural Research 29:205-223.

Dreccer, M.F., A.F. van Herwaarden, and S.C. Chapman. 2009. Grain number and grain weight in wheat lines contrasting for stem water soluble carbohydrate concentration. Field Crops Research 112:43-54.
Ehdaie, B., G.A. Allosh, and J.G. Waines. 2008. Genotypic variation in linear rate of grain growth and contribution of stem reserves to grain yield in wheat. Field Crops Research 106:34-43.

Egli, D.B. 1990. Seed water relations and the regulation of the duration of seed growth in soybean. Journal of Experimental Botany 41:243-248.

Fischer, R. 1985. Number of kernels in wheat crops and the influence of solar radiation and temperature. Journal of Agricultural Science 105:447-461.

Fischer, R.A., and D.R. Laing. 1976. Yield potential in a dwarf spring wheat and response to crop thinning. Journal of Agricultural Science 87:113-122.

Foulkes, M.J., R. Sylvester-Bradley, and R.K. Scott. 2002. The ability of wheat cultivars to withstand drought in UK conditions: Grain yield formation. Journal of Agricultural Science 138:153169.

Hasan, A.K., J. Herrera, C. Lizana, and D.F. Calderini. 2011. Carpel weight, grain length and stabilized grain water content are physiological drivers of grain weight determination of wheat. Field Crops Research 123:241-247.

Hay, R.K.M., and E.J.M. Kirby. 1991. Convergence and synchrony a review of the coordination of development in wheat. Australian Journal of Agricultural Research 42:661-700.

Jandel Scientific. 1991. Table Curve V. 3.0. User's manual version 3.0 AISN software. Corte Madera, San Rafael, California, USA.

Lizana, X.C., R. Riegel, H. Gomez, A. Isla, S.J. McQueen-Mason, and D.F. Calderini. 2010. Expansins expression is associated with grain size dynamics in wheat (Triticum aestivum L.) Journal of Experimental Botany 61:1147-1157.

Miralles, D.J., C.F. Dominguez, and G.A. Slafer. 1996. Grain growth and post-anthesis leaf duration in dwarf, semidwarf and tall isogenic lines of wheat. Journal of Agronomy and Crop Science 117:115-122.

Monteith, J.L. 1984. Consistency and convenience in the choice of units for agricultural science. Experimental Agriculture 20:105117.

Pepler, S., M.J. Gooding, and R.H. Ellis. 2006. Modelling simultaneously water content and dry matter dynamics of wheat grains. Field Crops Research 95:49-63.

Rondanini, D.P., A.I. Mantese, R. Savin, and A.J. Hall. 2009. Water contents dynamics of achene, pericarp and embryo in sunflower: Associations with achene potential size and dry-down. European Journal of Agronomy 30:53-62.

Saini, H.S., and M.E. Westgate. 2000. Reproductive development in grain crops during drought. Advances in Agronomy 68:58-96.

Sala, R.G., M.E. Westgate, and F.H. Andrade. 2007. Source/sink ratio and the relationship between maximum water content, maximum volume, and final dry weight of maize kernels. Field Crops Research 101:19-25

Sandaña, P., C.I. Harcha, and D.F. Calderini. 2009. Sensitivity of yield and grain nitrogen concentration of wheat, lupin and pea to source reduction during grain filling. A comparative survey under high yielding conditions. Field Crops Research 114:233-243.

Savin, R., and G.A. Slafer. 1991. Shading effects on the yield of an Argentinian wheat cultivar. Journal of Agricultural Science 116:17.

Schnyder, H., and U. Baum. 1992. Growth of the grain of wheat (Triticum aestivum L.) The relationship between water content and dry matter accumulation. European Journal of Agronomy 1:51-57.

Serrago, R.A., I. Alzueta, R. Savin, and G.A. Slafer. 2013. Understanding grain yield responses to source-sink ratios during grain filling in wheat and barley under contrasting environments. Field Crops Research 150:42-51.

Serrago, R.A., R. Carretero, M.O. Bancal, and D.J. Miralles. 2011. Grain weight response to foliar diseases control in wheat (Triticum aestivum L.) Field Crops Research 120:352-359.

Shearman, V.J., R. Sylvester-Bradley, R.K. Scott, and M.J. Foulkes. 2005. Physiological processes associated with wheat yield progress in the UK. Crop Science 45:175-185. 
Slafer, G.A., E.H. Satorre, and F.H. Andrade. 1994. Increases in grain yield in bread wheat from breeding and associated physiological changes. Chapter 1. p. 1-68. In G.A. Slafer (ed.) Genetic improvement of field crops. Marcel Dekker, New York, USA.

Slafer, G.A., and R. Savin. 1994. Source-sink relationships and grain mass at different positions within the spike in wheat. Field Crops Research 37:39-49.
Sokal, R.R., and F.J. Rohlf. 1995. Biometry. The principles and practice of statistics in biological research. $3^{\text {rd }}$ ed. W.H. Freeman and Company, New York, USA.

Zadoks, J.C., T.T. Chang, and C.F. Konzak. 1974. A decimal code for the growth stages of cereals. Weed Research 14:415-421.

Zhang, H., N.C. Turner, and M.L. Poole. 2010. Source-sink balance and manipulating sink-source relations of wheat indicate that the yield potential of wheat is sink-limited in high-rainfall zones. Crop and Pasture Science 61:852-861. 